\title{
"An interesting time in my childhood": Thinking about storied experience to understand complexities of curriculum making and diversity
}

\author{
Elaine Chan \\ University of Nebraska-Lincoln \\ United States
}

\begin{abstract}
This paper highlights ways in which examining the storied experience of students may enhance our understanding of the complexities of curriculum making and diversity. Teachers, administrators, and other members of a diverse urban school implemented curriculum, practices, and policies that suggested a commitment to acknowledging the home cultures, languages, and religions that students brought to school. Examination of one Chinese student's "stories of experience" (Connelly \& Clandinin, 1990), however, revealed nuances and unexpected complexities of balancing integration into mainstream peer groups in school while growing up in an immigrant home. The nuances highlight ways in which schooling may contribute to shaping the ethnic identity of immigrant and minority students in ways that are much more complex than realized by teachers, administrators, and policy makers.
\end{abstract}

\section{Introduction \\ An Interesting Time in My Childhood}

An interesting time in my childhood was when I was four years old, and my Dad, my Mom and I went to China to get my sister. My parents didn't bring my sister to Canada when they came, because their trip from China to Canada was dangerous. Because my sister lived with my aunt until she was six, she didn't really remember my mom. But when my sister came to Canada, she and I developed a very good relationship. (Student Journal Entry, April 12, 2002)

Lisa submitted the above journal entry as part of a class assignment to "Write about an interesting time in your childhood" during the spring term of her seventh grade year. She wrote about meeting her sister for the first time. The details revealed in this journal entry provide a 
glimpse of the complexity of immigration for her family and allude to factors that may have contributed to shaping her sense of identity as a Chinese Canadian and challenges she may experience as she attempts to balance affiliation to her home and school cultures as a middle school student.

I first heard about Lisa prior to meeting her in person. During the first week of school, Lisa's homeroom teacher, Mr. Cabott, told me that about half of his new seventh grade students were the younger siblings of students he had taught in eighth grade the previous year. He said, "And Lisa is Annie's younger sister. But they have different last names" (Chan, E., Field notes, September 2001). Intrigued, I asked for further details. Mr. Cabott explained that Annie's last name is "Huang" while her younger sister's last name is "Wong." This brief conversation raised questions in my mind about ethnic identity and multicultural education that later guided my interactions with Lisa, Annie, and their teachers.

In this paper, I examine the storied experience of a Chinese Canadian student to inform my understanding of the complexities of curriculum making and diversity. I consider the interaction of culture and curriculum, to explore ways in which participation in the home and the school curriculum interacted to contribute to shaping the ethnic identity of an urban middle school student born into an immigrant Chinese family. I consider questions such as: How is Lisa's home culture addressed in her school context? Are there ways in which her learning about her family's culture at home intersect with her learning in her school curriculum? What kinds of challenges does Lisa encounter in her school community where Chinese is acknowledged to varying degrees but where English language and Canadian school practices prevail? What are some of the ways in which she feels connected to her home culture? and, Are there ways her teachers could support the development and maintenance of her family's home language and culture through the mandated school curriculum? ${ }^{\mathrm{i}}$

\section{Review of Existing Research}

\section{Increasingly Diverse Society}

North American society is becoming increasingly diverse (US Census Bureau, 2010; 2011; Statistics Canada, 2011), and this diversity is reflected in schools. There has been substantial growth in the body of research literature addressing the curricular needs of students of diverse backgrounds and the challenges of designing, implementing, and assessing curriculum for a diverse student population. We know more about the challenges that individuals of diverse backgrounds may encounter in schools and ways in which resources and programs may be made more accessible to socially and culturally diverse students. Cummins (1996, 2001), Gay (2010), and Nieto and Bode (2011), for example, advocate for the sharing of student knowledge about their cultural backgrounds as a curricular resource, and Cummins et al. (2005), Igoa (1995), and Wong-Fillmore (1991a, b) emphasize the importance of incorporating knowledge about home cultures and languages in the school curriculum. Paley's (1995) integrated curriculum had parents and children discussing ethnic values, rituals, and individual cultural experiences through family stories to foster a sense of community within the classroom, and Banks' (1995) work highlights the importance of the inclusion of culture in the curriculum as an opportunity for students to develop positive racial attitudes. Indeed, we have much more information about the importance of culturally-sensitive and culturally-relevant curriculum that affirms the diversity of students in schools (Gay, 2010; Ladson-Billings, 2001; Nieto \& Bode, 2011) than in the past. 


\section{Need for Further Acknowledgement of Diversity in Schools}

Nonetheless, there is a need for further knowledge about how we might engage students of diverse backgrounds more fully in school communities. Valenzuela (2009), Valdes (1996), and Lomawaima (2003; Lomawaima \& McCarty, 2006) discuss ways in which some of the existing practices in American schools might be perceived as suggesting an underlying lack of respect for the home cultures of students of diverse backgrounds. Cummins et al. (2005), for example, claim a lack of recognition for the potential of cultural and linguistic knowledge as societal resources, stating that it is difficult to argue that we are teaching the whole child when school policies dictate that students "leave their language and culture at the school-house door" (p. 38). Gandara and Hopkins (2010) outline ways in which restrictive language policies may contribute to further disengagement of English language learners in school; not only do they lack English language proficiency to interact with native English speaking peers, but they are not permitted to use their home languages to build friendships with peers of the same cultural background. Lomawaima and McCarty (2006) outline tensions when Native American students perceive the need to abandon their home cultures in order to be accepted by mainstream cultural groups. In some of my own work examining my experiences of "ethnic identity in transition" (Chan, 2003), I refer to the intersection of culture and curriculum as "conflicting stories to live by" (Chan, 2010) when students from minority backgrounds feel caught between school and home when expectations in the two places differ significantly (Clandinin, Connelly, \& Chan, 2002). Hamann and Zuniga (2011) go so far as to refer to the chasms between school curriculum and the lack of acknowledgement for the home cultures of immigrant and minority students as "ruptures."

This body of work reveals and outlines details of ways in which balancing affiliation to home and school cultures may be difficult for students of minority background. The work suggests that there remains much we do not yet know about the "cultural harmonies and tensions" (Clandinin \& Connelly, 2002) that students of diverse social and cultural backgrounds experience. Carger (1996), Chan and Ross (2009), Huber, Murphy, and Clandinin (2011), Phillion (2002), Chan and Schlein (in press), and Schlein and Chan's (2012) work examining the nuances of cross-cultural and multicultural teaching and learning using a narrative inquiry approach are among the growing body of work addressing the intersection of culture and curriculum in schools in an experiential way.

Clandinin's (1986) long-term, narrative inquiry work with an elementary teacher offers a glimpse of the ways in which teachers' identities and experiences outside of the classroom may inform and shape their curricular decisions. This body of "teacher knowledge" gained through personal and professional experiences (Clandinin \& Connelly, 1996) - termed "personal practical knowledge" (Connelly \& Clandinin, 1990)—differs from the "knowledge of teachers" (Clandinin \& Connelly, 1996) that is gained from expert sources such as professional documents and sources, in that it is unique to the circumstances and contexts of each teacher.

Just as teachers' "narratives of experience" (Connelly \& Clandinin, 1988) provide details of the complexity of teacher lives on school landscapes that extend beyond the confines of school life, examination of students' experiences in school suggest a rich intersection of influences contributing to their curriculum experiences and sense of identity. Examination of the details of students' experiences of curriculum offer a glimpse of the importance of these details in shaping the identity and knowledge of students (Clandinin, et al., 2006; Chan, 2007; 2010; Huber, et al., 2011; Clandinin, Steeves, \& Caine, 2013). Details of students' experiences as they move back and forth from home to school and then back again may be understood as an 
intersection of learning in the home and community, with learning through the school curriculum. Recognition of the interconnectedness between experience and education in this examination of the intersection of home and school learning is grounded in Dewey's (1938) work.

Recognizing these interconnections in learning, Huber, et al. (2011) argue that understandings of curriculum should, appropriately, extend to learning that is experienced outside of school, such as in families and communities. They describe this work as "a curriculum of lives" (Clandinin, et al., 2013), acknowledging the influences of family and community experiences in contributing to and extending the learning of children in ways much more complex than previously perceived.

Shifting the focus to students and their families informs our understanding of the complexity of curriculum, by revealing the potential contribution of experiences beyond classrooms and schools to the school learning of students. In the process, our understanding of the complexities of teaching and curriculum are enriched.

\section{Purposes}

In this paper, I explore what we might learn about students' cultural experiences by looking more closely at ways in which they share and reveal aspects of their cultural knowledge through participation in school curriculum. Using a narrative inquiry approach, I examine "harmonies and tensions" (Clandinin \& Connelly, 2002) of one student, Lisa's, "stories of experience" (Connelly \& Clandinin, 1990) of the inclusion of culture in her school curriculum. Through interaction with Lisa and her teachers about their experiences at Bay Street School, I learned about nuances of ethnic identity formation and about challenges teachers may encounter when attempting to implement curriculum that acknowledges students' home culture.

Interwoven into this study examining Lisa's experiences of balancing her home and school communities is my experience of drawing upon my own experiences as a child growing up in an immigrant household; I consider ways in which the lens of my childhood experiences inform my interpretation of Lisa's experiences. I explore ethical considerations of researcher interpretation of student experiences when the researcher, while recognizing the potential for extreme differences within the group, also claims to be knowledgeable about some aspects of the ethnic group through membership in the same group.

\section{Theoretical Framework}

Building upon Dewey's (1938) theory of the interconnectedness between education and experience, I refer to all that occurred within and beyond Lisa's school context as education. I consider the challenges of capturing the complexities of student life in the process of "composing lives in transition" (Clandinin, et al., 2013) as I explore ethnic identity formation in relation to school curriculum. Stories of experience gathered through interaction with the students on the school landscape using a narrative inquiry approach (Clandinin \& Connelly, 1994; 2000) provide a means of understanding the students' experiences. Huber, et al.'s (2011) notion of narrative inquiry as relational multiperspectival inquiry runs deeply throughout this piece. 


\section{A Narrative Inquiry Approach to Learning about Lisa's Experiences}

Using a narrative inquiry approach, which focuses on inquiring into stories of experience (Connelly \& Clandinin, 1988; Connelly \& Clandinin, 1990; Clandinin \& Connelly, 1994), I conducted participant observations, took part in all aspects of classroom life, attended staff meetings and school events, and interacted with members of the Bay Street School community to learn about ways in which issues of ethnicity, culture, and language played out in the school context. Lisa, her classmates, and her teachers were research participants in this study.

Observations were conducted over two years as Lisa and her classmates began seventh grade and continued until they graduated from eighth grade. All interactions took place while I was a researcher in Lisa's classroom, as I engaged participants in conversations about their experiences of culture in the curriculum in the context of regular school activities.

Descriptive field notes and research journal entries were made following classroom observations, participation in the classroom and school, and conversations with Lisa, her classmates and her teachers. Research journal entries, interview transcripts, and field note records were computerized, and all data, including samples of student work, communication between home and school, community announcements, and media coverage were filed into an existing research archive system.

\section{Learning about Lisa}

\section{Lisa's Family}

I present here details of Lisa's experiences as a Chinese Canadian in the Bay Street School and neighboring community. Lisa was born into a Cantonese-speaking immigrant Chinese family in Toronto, Canada. Her brother, Matthew, five years younger, was also born in Toronto. Her parents and her elder sister, Annie, two years older than Lisa, were born in Guongdong province of China. Lisa's parents originally settled in a community off the Main Street area of Toronto when they first arrived in Canada but moved into the Bay Street School community when Lisa was eight years old. All three children attended Bay Street School until Annie graduated from eighth grade and moved to the local high school. Lisa moved to eighth grade while their younger brother, Matthew, began third grade.

Lisa's father owns and runs a bakery in a neighborhood shopping area. The family lives in rooms above the bakery, along with workers who rent out rooms in the same building and work in the bakery. The workers in the bakery help to keep an eye on Lisa and Matthew during after-school hours when their father and mother are working. Lisa's father is often away from the bakery, traveling on business to deliver the baked goods to Chinese grocery stores and to expand their customer base in various places in Canada and the United States. Her mother assembles computers at a company located in the suburbs north of Toronto, near where her aunt, her mother's only relative in Canada, lives. Lisa and Annie have both spoken about how the family eats their meals with the workers in the bakery. The workers usually prepare the evening meal for the family since their mother does not return home until later in the evening after commuting on public transportation. Lisa's exposure to Chinese culture is reinforced through interactions with family members and through regular interaction with the bakery workers. Lisa has spoken about how the workers taught her to play games popular in China when they were children. One day, she described a marble game that I have heard about from my mother's own childhood memories in China. 
Subsequent interactions with Lisa and other members of the Bay Street School community helped to inform my understanding of Lisa's experiences as a second generation Chinese Canadian. Kerby (1991) stated that "experiences come to one not in discrete instances but as part of an ongoing life" (p. 16). I was struck by how I learned about Lisa's life as a Chinese Canadian through tidbits of information she shared about her family and her school and home life as she interacted with her friends and classmates, her teachers, and with me in her school context. Lisa referred to family members when she told me about after-school and weekend excursions, and I heard about the Chinese workers in her father's bakery when she needed to call home for permission to stay at school later than usual to finish a research project or to help out at school events such as "Curriculum Night" or "Multicultural Night." I learned about the circumstances of her family's arrival in Canada when she wrote about her sister, Annie's, arrival in Canada in her writing assignment for her teacher.

In the journal entry presented at the beginning of this paper, Lisa referred to the circumstances under which her family emigrated from China to settle in Canada. She also spoke about changes within her family when her sister arrived in Canada to join her family after having spent her first six years in the care of her maternal aunt in China.

Until Annie's arrival, Lisa was an only child, since their younger brother was born after Annie's arrival. Annie's arrival in Canada represented a significant change for both Lisa and Annie. Annie thought of her aunt as her mother figure, had not seen her parents since she was a baby, and had never met her younger sister, Lisa. Annie arrived in Toronto at the age of six to a family who was her own but who must have felt as foreign to her as a family of strangers might, since they were not a part of her daily life during her years in China living with her aunt.

Moreover, Lisa and Annie's relationship as sisters was different than what might be expected in a traditional Chinese family. In China, as the older sister, Annie might have been expected to look after her younger siblings and to guide them. In her situation, however, she needed to rely on Lisa, her younger sister, for help expressing even basic needs since she did not initially speak English at all. Lisa, on the other hand, was fluent in English since she was born in Canada and was familiar with a routine that involved shifts from Chinese to English and from home to daycare, since she had attended an English-run daycare since the age of two while her parents worked. Since Lisa was relatively comfortable using English, she helped her older sister in a way that an older sister in a Chinese family might be expected to guide a younger sister. In China, Annie was raised with her older cousin and was coddled as the youngest child in the family. Since "she was another person's child," Lisa said, she was raised with special consideration. Annie needed to learn about her new family, her new home, and a new schedule of daily activities after her family returned to Toronto from China. Lisa remembers Annie as not especially liking her at first. She said she had to fight with her to give her a goodnight kiss, and Annie did not want to share her belongings or her sweets with her younger sister. Lisa spoke about how she remembered looking over at her sister in their daycare playground to see Annie brushing large flakes of snow from her coat collar as if they were insects.

The initial awkwardness and confusion that Lisa, Annie, and other family members may have experienced upon Annie's arrival in Canada may seem relatively insignificant in the large scheme of immigration and settlement when so many immigrants have suffered through war, abuse, refugee camps, and violent loss of family members. These details, however, provide a glimpse of the complexity of immigration for the individuals involved. The experience of immigration in Lisa's family has likely contributed to shaping how she and her sister Annie see themselves as members of the Chinese community as well as their Canadian community. The 
differences may be manifested in various ways. On one occasion, for example, the differences may have been manifested in the friends to whom they gravitated. While both Lisa and Annie's friendships tended toward groups of girls in their classes who also had a Chinese heritage, there were subtle differences that might have reflected differences in their early childhood experiences. While Annie often spoke in Chinese with her group of friends, some of whom were Chinese-born and had arrived in Canada as children, Lisa always spoke in English when communicating with her Chinese friends in school. I witnessed an interaction one afternoon when Annie and a new classmate excitedly told their teacher of the discovery that both had in common the small village in Guangdong province in the south of China where they had lived as children. Lisa would be unlikely to have had the same sense of connection to a place in China she had visited only briefly with her family as a preschooler. Reflection upon the circumstances of immigration and settlement in Lisa's family and the ways in which her family is connected to other members of the Chinese community in China and in Canada highlight the complexities of immigration.

\section{Bay Street School Community}

While the specific details surrounding Lisa's family's arrival in Toronto are unique to her family, the need to adapt to and overcome challenges of immigration and settlement is an experience shared among many peers and classmates in her school community. To begin with, Lisa is among a large number of students of Chinese descent at Bay Street School. From a teacher-developed "Every Student Survey" administered to students during Lisa's seventh-grade year, 293 of the 686 students attending the school spoke at least one dialect of Chinese (Ross \& Chan, 2008). The number of students who speak Chinese, whether Cantonese, Mandarin, or Fujianese, freely in the school community is such that Chinese and English co-exist, and the availability of people with whom to interact and ask about Chinese language and culture validate its presence as a strong influence in the school. The use of Cantonese-Lisa's family's dialect of Chinese - at Bay Street School is common and well accepted. I have heard both Lisa and Annie speak in Chinese with teachers, peers, and their parents during classes and school-sponsored events such as "Curriculum Night," "Multicultural Night," band concerts, and graduation.

Lisa's family lives in a neighborhood located just minutes from the largest and most wellknown of the five Chinatowns in the Toronto area. Toronto has a high proportion of immigrants, second only to Miami, Florida (Statistics Canada, 2003b), with the Chinese community as the largest visible minority group (Statistics Canada, 2003a, c) and Chinese is the top non-official language spoken in Toronto (Statistics Canada, 2003c). Lisa's family lives within walking distance of a commercial area complete with restaurants, grocery and variety stores, bakeries, medical, dental, and legal services, travel agents, and clothing and book stores where Cantonese, the language used in her family and by a large number of the Chinese community in Toronto, is the language of communication. Moreover, the area surrounding Bay Street School is populated with many recent immigrants, including many from China. Although Lisa's family often leaves the neighborhood to shop for clothes and food or to visit relatives who live in the suburbs north of Toronto, many of the families at Bay Street School rarely leave this community, where they may survive quite comfortably speaking only in Chinese. The services available are such that they do not need to leave except by choice. In fact, many of the grandparents from the neighborhood who come to the Parent Centre in the school with their preschool-aged grandchildren do not speak English or speak only at a very basic level, although a number of them have been in Canada for over 15 years. 
The ethnic and linguistic diversity of the neighborhood in which Lisa lives is reflected in the student population at Bay Street School. Based on the results of the "Every Student Survey" referred to earlier, students were found to speak 31 languages and dialects and represent 39 countries (Ross \& Chan, 2008). This diversity is supported in the school through a wide range of programs and services. An International Languages program is integrated into the school curriculum to provide students with language instruction in Cantonese and Mandarin Chinese, Arabic, Spanish, Vietnamese, and Swahili. The use of maternal languages is both common and accepted throughout the school, and interaction between school staff and non-English speaking members of the students' families is facilitated through the availability of settlement workers, interpreters, and translators who translate correspondence between the school and the students' homes into six different languages. Through classroom observations and participation in school events and activities, I have seen administrators and teachers at Bay Street School incorporate into the curriculum lessons addressing issues of cultural diversity, racism, equality, and injustice, and demonstrate a desire to learn about the cultural and linguistic backgrounds of the students. I describe some of these practices and lessons in upcoming sections.

\section{"An English one for me, a Chinese one for my mother": Addressing Family Diversity Through School Practices}

One day during the winter term of her seventh-grade year, I watched Lisa take two copies of a school notice informing parents of the departure of the vice principal for a nearby school to become a principal. She said out loud as she slipped the notices into her binder, "An English one for me, a Chinese one for my mother." I had seen Annie pick up two copies of the curriculum her eighth-grade teachers had prepared for "Curriculum Night" a year earlier and say nearly the same thing. Annie and Lisa's parents do not read English very well, and Annie and Lisa do not read Chinese very well. Lisa and Annie's practice of taking a Chinese notice for their parents and an English one for themselves reinforces the importance of accommodations such as this one at Bay Street School, where correspondence between the school and the students' homes is facilitated through the availability of notices translated into the students' home languages. It was an example of ways in which practices at Bay Street School might accommodate for the language and cultural diversity of the students and their families.

Bay Street School is among the small number of schools in the district where International Language classes are integrated into the regular school day. Students at the school choose from Cantonese Chinese, Mandarin Chinese, Spanish, Black Culture and Language, Arabic, and Vietnamese International Language classes. Each student from kindergarten to eighth grade spends 45 minutes, four times a week, in International Language class.

The students' experience of Chinese language classes as part of the regular school day differs significantly from what I experienced as a child attending Chinese classes on weekends in a community far from my home. Furthermore, the proximity of Bay Street School to a neighborhood where there are many Chinese residents enhances Lisa's exposure to Chinese language and culture, resources to learn about Chinese language and culture in her school and in the community, and access to Chinese learning resources and Chinese-made products that are popular among teens. With the large population of Chinese students in her school, the inclusion of Chinese language classes within the regular school curriculum, the acceptance of Chinese language use within the school, and its proximity to the large Chinatown where many students live, Lisa has much more exposure to Chinese language and culture than I did as a child. 
Moreover, Lisa's peers are accustomed to hearing Chinese spoken within the school; they know Lisa takes Cantonese Chinese for International Language class and that she celebrates Chinese holidays.

Whether Lisa would be able to speak Chinese and be knowledgeable about Chinese culture if she did not live in this community and attend Bay Street School is not known. However, the strong Chinese presence likely contributes to a sense of support for the development of Chinese language proficiency and knowledge about cultural traditions. In comparison to my own childhood experiences, Chinese culture is more likely to be acknowledged outside the home, and Chinese food has become more mainstream as the number of Chinese restaurants has increased, and Chinese food has become more commonly eaten among non-Chinese populations within the city. In addition, Chinese festivals such as the Dragon Boat Races, New Year's, and Autumnal Moon Festivals are now more commonly celebrated in the greater community (Chan, 2003). The extent of exposure to Chinese culture and language in Lisa's neighborhood likely contributes to shaping her sense of ethnic identity as a Chinese Canadian as involving an interaction of both Chinese and non-Chinese influences in her school and neighborhood community. The lack of exposure to Chinese culture and language outside my home during my own childhood likely contributed to my sense of ethnic identity as a Chinese Canadian as involving a clear distinction between places where Chinese language and traditions were celebrated and places where they were not. Lisa and her peers, in contrast, seem to have opportunities to learn about the home cultures of their peers as cultural practices arise in conversations with peers and teachers in the context of their classroom and school and to participate in discussions about nuances of diversity during lessons. Aspects of different cultures and languages are incorporated into the school curriculum such that I do not perceive the same kind of division between home and school culture that I perceived during my own childhood (Chan, 2003).

\section{Further Complexities of Ethnic Identity: Narratives of Maternal Language Acquisition and Loss}

Yet despite this seeming acceptance of her family's culture and language in her school context, there are nuances, underlying influences, that likely contribute to shaping Lisa's sense of ethnic identity and sense of belonging in her ethnic community. To begin with, Lisa's proficiency in Cantonese is connected to her sense of ethnic identity in that maternal language proficiency shapes her ability to communicate with other members of the Cantonese-speaking Chinese community. Although Lisa is able to speak in Cantonese with her parents and does relatively well in her Chinese International Language class, she is not confident in her ability to read, speak, or write Chinese. Even in Chinese class, she does not speak to her peers or her teacher in Chinese, preferring to incorporate Chinese vocabulary into otherwise English sentences. This is especially obvious given that many of her peers have spent a good part of their childhood in China and are therefore able to read and write Chinese at a relatively high level of proficiency, but they are in her Chinese class only because they are at the same grade level in the Canadian school system.

One day, when I asked Lisa about the Chinese characters in her International Language text, she asked her friend Ai Mei, who arrived at Bay Street School from Fujian province of China in the second grade and who had a foundation in Chinese before leaving China, for assistance. Ai Mei reads Chinese relatively well, but she provides the pronunciation for the characters in Mandarin since she only speaks very limited Cantonese, learned from Cantonese- 
speaking classmates and friends at Bay Street School. Her own family speaks Fujianese, and she acquired Mandarin through schooling in China before arriving in Canada and through her Mandarin Chinese International Language class at Bay Street School. Lisa then referred back to recent lessons from her Chinese text and matched Ai Mei's Mandarin pronunciation with the Cantonese equivalent. Another day, I asked Lisa about the Chinese character on the front of her T-shirt. I actually knew the character but was curious as to whether she knew it as well. Lisa called over to Ai Mei for the pronunciation, and when Ai Mei provided it for her in Mandarin, she repeated the Mandarin pronunciation to me. I wondered whether she did not know it. I commented that the word is often displayed during Chinese New Year but that it is placed upside down. The pronunciation for the word "upside down" in Cantonese sounds like the pronunciation for the verb "to arrive;" when this character is turned upside down, it means that luck will arrive. The symbol for "luck," turned upside down to symbolize the "arrival of luck," is displayed prominently on doors in Chinese households during the Lunar New Year season. Lisa must have known this as well, because when she heard me say this, she corrected the Mandarin pronunciation Ai Mei had provided previously and told me that the Cantonese pronunciation for the character was "fook," not "foo," the Mandarin pronunciation Ai Mei had provided. Lisa knew about the Chinese custom of turning the character upside down and was likely familiar enough with the word to draw on this knowledge but not familiar enough to recall it spontaneously or independently. Growing up in a Chinese family in a community near Toronto's Chinatown, she has likely been exposed to many Chinese customs and practices. Although she may not understand or agree with the rationale for the practices, she is nonetheless aware of many of them.

As I reflected upon Lisa's knowledge of and proficiency in Chinese, I thought about her limited reading ability in Chinese and her tendency to prefer English even in the presence of Chinese peers and teachers when compared to her Chinese-born peers. Although Lisa speaks Cantonese with her parents, relatives, and the people who work in her father's bakery, a combination of both English and Cantonese with her International Language teacher at Bay Street School, her sister, and members of her church community, she speaks in English with everyone else, including her Chinese classmates who have been in Canada long enough to speak English relatively well. She only uses Cantonese with Chinese students who do not speak or understand English well, but there are not many Chinese students who fall into this category in her homeroom class; students going into the ESL Reception Class ${ }^{\mathrm{ii}}$ at Bay Street School in the past few years have been more likely to speak Mandarin. Since Lisa does not speak Mandarin, she does not use Chinese with these students either. Despite opportunities to learn and to use Chinese in her school, home, and neighborhood settings, she still struggles with acquiring Chinese fluency.

Within the body of literature addressing the experiences of North American-born students of immigrant parents, lack of proficiency in the maternal language has often been identified among the challenges of individuals born or raised outside of their family's home country. The predominance of English, combined with limited exposure or opportunities to develop proficiency in the family's home language, often contributes to: limited proficiency in the home language with which to communicate with non-English speaking parents and family members; feelings of isolation and alienation from their ethnic community; and difficulties accessing their family's culture (Cummins, 1996; 2001; Cummins \& Danesi, 1990; Igoa, 1995; Khu, 2001; Kouritzin, 1999; Wong-Fillmore, 1991a; 1991b). Wong-Fillmore (1991a) elaborated upon the dire consequences of maternal language loss when parents lose the ability to "convey to 
the[ir children] their values, beliefs, understandings, or wisdom about how to cope with their experiences. They cannot teach them about the meaning of work, or about personal responsibility, or what it means to be a moral or ethical person in a world with too many choices and too few guideposts to follow" (p. 343).

Sometimes, individuals struggled with finding the language to inform family members of events of personal and professional success (Kouritzin, 1999). Lisa, for example, lacked fluency in Cantonese to communicate her pride in her extraordinary academic accomplishments. Toward the end of her eighth-grade year, Lisa was named valedictorian of her graduating class. A few days before the graduation ceremony, she was practicing her speech in her classroom after school with Mr. Cabott, her homeroom teacher. Mr. Cabott asked her whether she had told her parents about the honor of being named valedictorian, and Lisa responded that she had. Mr. Cabott then asked what they had said about it and whether they understood what it meant. Lisa explained that her mother understood a little after she had told her that she was doing what Annie's friend, Liz, had done a couple of years ago at their eighth-grade graduation. She said that her father did not understand at all. Mr. Cabott emphasized she should be sure to explain it to them.

When I heard Lisa talk about how her parents did not know about the details of what she was doing in school, I could relate to what she was saying, because there are aspects of my school and work worlds that I have not shared with my parents. A lack of proficiency in Chinese and a lack of common context from which events in school could be put into a context my parents would understand further hinders me. Drawing upon my own experiences helped to enrich my understanding of Lisa's hesitation in explaining to her parents in greater detail her wonderful accomplishment as valedictorian of her graduating class. At the same time, I was mindful of the likelihood of alternative interpretations as well.

Recognition of the role of maternal language loss, and by association, the possible role of school in contributing to or facilitating this loss through its explicit focus on English as the language of instruction and communication in school, highlights the complexity of intersections between student diversity and curriculum. As we further consider possible contributions of outof-school experiences in shaping student learning, examination of the details of student narratives offers us a glimpse of the ways in which participation in school curriculum might be experienced by students from diverse social and cultural backgrounds.

\section{The Blurring of Lines between Home and School, as Seen Through Lisa's Narratives of Experiences}

Examination of Lisa's stories of experience (Connelly \& Clandinin, 1990) provided a glimpse of the interaction of culture and curriculum, to inform our understanding of the ways in which influences in the home and school environment may intersect to contribute to shaping a sense of ethnic identity for students of diverse social and cultural backgrounds. Lisa's writing about "an interesting time in [her] life" for a class assignment introduced details of her life, and prompted questions about her family's journey of immigration, her sister's experiences in China as well as after her arrival in Canada, her family's political affiliation, her parent's work circumstances, her family's living circumstances, her extended family, interaction with other Cantonese speakers in Toronto, and Cantonese language proficiency, to begin with. Some of these questions arose in the context of her participation in her school curriculum or in interactions with her teachers and peers, while others arose in interactions with extended family 
members, such as her maternal aunt who lives in the suburbs or the workers in her father's bakery who cook supper and eat with her family each evening. These interactions all had the potential to contribute to shaping her sense of ethnic identity. These questions do not, by any means, represent a complete list but serve as recognition of the issues related to culture and ethnic identity that were raised through writing about events in one student's life for the purpose of a curriculum assignment. A curriculum assignment that began in Lisa's classroom extended well beyond the confines of her school.

Huber, Murphy, and Clandinin's (2011) notion of narrative inquiry as relational multiperspectival inquiry is an apt description of an inquiry into ways in which curricular experiences may interconnect with experiences and influences outside the school context to contribute to the ethnic identity of a Chinese Canadian student such as Lisa. The web of interconnections that begin with Lisa who is the focus of this narrative inquiry extended to each person with whom Lisa interacts, quickly becomes expansive. This recognition of far-reaching influences from within to beyond classrooms highlights the potential of curricular experiences to extend beyond the context of the classroom or student where academic and social lessons begin, and for the potential influence of experiences beyond the classroom to contribute to shaping curriculum implemented within school and classroom contexts. Examination of Lisa's experiences in this narrative inquiry is "multiperspectival" through the many perspectives represented but also through its range of influences that go beyond her immediate home and school community through the experiences that each individual with whom she interacts brings to interactions with her. For example, her interactions with her sister, Annie, who experienced a different preschool context than did Lisa while she remained in China before her parents could return to bring her to join the family, introduces influences that intersect with those she brings to their interactions. A narrative inquiry into Annie's experiences would undoubtedly include experiences that differ, but that may intersect, with those featured in this inquiry focusing on Lisa's experiences. Similarly, the idea of far reaching interconnections extending beyond those of relevance in the current context, could be applied to Lisa's teachers, her Canadian born Chinese friends, her Chinese born classmates, her Chinese-born older sister, her younger brother, her parents, the older Cantonese speaking workers in her family's bakery, her homeroom teacher who does not speak any Chinese at all, and even to myself, as a Canadian-born Chinese person who spent most of her life in city less culturally diverse than Toronto where she lives.

Interwoven into this examination of Lisa's experience is an exploration of researcher interpretation of student experiences, when the researcher claims to be knowledgeable about the ethnic group through her own membership in the same group. As I learned about Lisa's experiences, I could not help but refer to my own experiences. I drew upon my experiences as a second generation Chinese Canadian who was educated in Canadian schools as a data source to inform my understanding of the interaction of culture and curriculum in a school setting.

My researcher voice interweaves through my examination of Lisa's experiences in school, and my interpretation of her experiences colors my understanding of her experiences in countless ways. Recognition of this interweaving of researcher and participant experiences offers further support for the many ways in which narratives of experience of one individual may intersect with those of another, such that inquiry into one person's experiences may also interconnect with inquiry into the experiences of another.

Recognition of the importance of curriculum as a "life making process" (Huber, et al., 2011) that extends notions of curriculum as a "course of life" (Connelly \& Clandinin, 1988) further reinforces the importance of acknowledgment for learning that takes place beyond an 
academic, in-school context. This learning has the potential to enrich students' experiences far into the future even if the impact of such learning does not seem pressing at this point in time.

This acknowledgment of curriculum that extends beyond the classroom, and recognition of the interconnections between school and out of school learning in contributing to curriculum as a life making process, reinforces the importance of learning beyond school and classrooms. For students such as Lisa, who are academically strong and with strong friendships with peers, there is little urgency to researching challenges she may encounter in her classroom, school, or neighborhood community when there are so many others with more pressing challenges. Recognition of curriculum as a "life making process" (Huber, et al., 2011) adds further layers of complexities to questions about the role of schooling in contributing to the lives of students in the future and about challenges of integrating this curriculum with the academic curriculum.

\section{Educational Significance}

Examination of Lisa's stories of experience highlight complexities surrounding the intersection of culture and curriculum and reinforce the need to examine in further detail challenges teachers may encounter when attempting to acknowledge students' home cultures as a way of engaging students of minority background. This study acknowledges the contribution of an experiential approach to inform curricular decisions concerning students of ethnic minority background. Knowledge about the challenges of implementing curriculum for an increasingly diverse student population contributes to the field of Curriculum Studies by enhancing the ability of educators to meet the needs of students of ethnic minority background in mainstream schooling. This work has the potential to inform teaching practices, professional development for educators, and decision making pertaining to the development of curriculum policies for multicultural school contexts. In this way, this study contributes to a real-life understanding of the experiences of immigrant and minority students in North American schools and beyond.

\section{Acknowledgement of Funding Support}

This research was part of a larger study examining the ethnic identity of first generation Canadians in a multicultural school context, which was in turn embedded into a research project addressing cultural diversity on a school landscape. Both studies were supported by the Social Sciences and Humanities Research Council of Canada. 


\section{References}

Banks, J. A. (1995). Multicultural education: Its effects on students' racial and gender role attitudes. In J. A. Banks \& C. A. McGee Banks (Eds.), Handbook of research on multicultural education (pp. 617-627). Toronto, ON: Prentice Hall International.

Carger, C. L. (1996). Of borders and dreams: Mexican-American experience of urban education. New York, NY: Teachers College.

Chan, E. (2003). OP-ED. Ethnic identity in transition: Chinese New Year through the years. Journal of Curriculum Studies, 35(4), 409-423.

Chan, E. (2007). Student experiences of a culturally-sensitive curriculum: Ethnic identity development amid conflicting stories to live by. Journal of Curriculum Studies, 39(2), 177-194.

Chan, E. (2010). Living in the space between participant and researcher: Examining ethnic identity of Chinese Canadian students as a narrative inquirer. The Journal of Educational Research, 102(2), 113-122.

Chan, E., \& Ross, V. (2009). Examining teachers' knowledge on a landscape of theory, practice, and policy. Curriculum and Teaching Dialogue, 11(1 \& 2), 159-171.

Chan, E., \& Schlein, C. (in press). Standardized testing, literacy, and English language learners: Lived multicultural stories among educational stakeholders. In K. F. Malu \& M. B. Schaefer (Eds.), Research on teaching and learning with the literacies of young adolescents. Charlotte, NC: Information Age Press.

Clandinin, D. J. (1986). Classroom practice: Teacher images in action. Barcombe, Lewes, Sussex, UK: Falmer Press.

Clandinin, D. J., \& Connelly, F. M. (1994). Personal experience methods. In N. K. Denzin \& Y. S. Lincoln (Eds.), Handbook of qualitative research in the social sciences (pp. 413-427). Thousand Oaks, CA: Sage Publications.

Clandinin, D. J., \& Connelly, F. M. (1996). Teachers' professional knowledge landscapes: Teacher stories - stories of teachers - school stories - stories of schools. Educational Researcher, 25, 24-30.

Clandinin, D. J., \& Connelly, F. M. (2000). Narrative inquiry: Experience and story in qualitative research. San Francisco, CA: Jossey-Bass Publishers.

Clandinin, D. J., \& Connelly, F. M. (2002). Intersecting narratives: Cultural harmonies and tensions in inner-city urban canadian schools. Proposal submitted to the Social Sciences and Humanities Research Council of Canada. October, 2002. 
Clandinin, D. J., Connelly, F. M., \& Chan, E. (2002). Three narrative teaching practices - one narrative teaching exercise. In N. Lyons \& V. K. LaBoskey (Eds.), Narrative knowing in teaching: Exemplars of reflective teaching, research, and teacher education. New York, NY: Teachers College Press.

Clandinin, D. J., Huber, J., Huber, M., Murphy, M. S., Murray-Orr, A., Pearce, M., \& Steeves, P. (2006). Composing diverse identities: Narrative inquiries into the interwoven lives of children and teachers. New York, NY: Routledge.

Clandinin, D. J., Steeves, P., \& Caine, V. (2013). Composing lives in transition: A narrative inquiry into the experiences of early school leavers. Volume 16, Advances in Research on Teaching Series. Bingley, UK: Emerald Group Publishing.

Connelly, F. M., \& Clandinin, D. J. (1988). Teachers as curriculum planners: Narratives of experience. New York, NY: Teachers College Press.

Connelly, F. M., \& Clandinin, D. J. (1990). Stories of experience and narrative inquiry. Educational Researcher, 19(5), 2-14.

Cummins, J. (1996). Negotiating identities: Education for empowerment in a diverse society. Ontario, CA: CABE (California Association for Bilingual Education).

Cummins, J. (2001). Negotiating identities: Education for empowerment in a diverse society (2nd ed.). Los Angeles, CA: California Association for Bilingual Education.

Cummins, J., Bismilla, V., Chow, P., Cohen, S., Giampapa, F., Leoni, L., . . Sastri, P. (2005). Affirming identity in multilingual classrooms. Educational Leadership, 63(1), 38-43.

Cummins, J., \& Danesi, M. (1990). Heritage languages: The development and denial of Canada's linguistic resources. Toronto, ON: Our Schools/Our Selves Education Foundation; Garamond Press.

Dewey, J. (1938). Experience and education. New York, NY: Simon \& Schuster.

Gay, G. (2010). Culturally responsive teaching: Theory, research and practice. New York, NY: Teachers College Press.

Gandara, P., \& Hopkins, M. (Eds.) (2010). Forbidden language: English learners and restrictive language policies. New York, NY: Teachers College Press.

Hamann, E. T., \& Zuniga, V. (2011). Schooling and the everyday ruptures transnational children encounter in the United States and Mexico. In C. Coe, R. Reynolds, D. Boehm, J. M. Hess, \& H. Rae-Espinoza (Eds.), Everyday ruptures: Children and migration in global perspective (pp. 141-160). Nashville, TN: Vanderbilt University Press.

Huber, J., Murphy, M. S., \& Clandinin, D. J. (2011). Places of curriculum making: Narrative inquiries into children's lives in motion. Bingley, UK: Emerald Group Publishing. 
Igoa, C. (1995). The inner world of the immigrant child. New York, NY: St. Martin's Press.

Kerby, A. P. (1991). Narrative and the self. Bloomington, IN: Indiana University Press.

Khu, J. M. T. (2001). Cultural curiosity: Thirteen stories about the search for Chinese roots. Berkeley, CA: University of California Press.

Kouritzin, S. G. (1999). Face(t)s of first language loss. Mahwah, NJ: Lawrence Erlbaum.

Ladson-Billings, G. (2001). Crossing over to Canaan: The journey of new teachers in diverse classrooms. San Francisco, CA: Jossey-Bass.

Lomawaima, K. T. (2003). Educating Native Americans. In J. Banks (Ed.) Handbook of Research on Multicultural Education (2 ${ }^{\text {nd }}$ ed.) (pp. 441-446). New York, NY: JosseyBass.

Lomawaima, K. T., \& McCarty, T. L. (2006). To remain an Indian: Lessons in democracy from a century of Native American Education. New York, NY: Teachers College Press.

Nieto, S., \& Bode, P. (2011). Affirming diversity: The sociopolitical context of multicultural education (6th ed.). New York, NY: Longman.

Paley, V. G. (1995). Kwanzaa and me: A teacher's story. Cambridge, MA: Harvard University Press.

Phillion, J. (2002). Narrative inquiry in a multicultural landscape: Multicultural teaching and learning. Westport, CT: Ablex.

Ross, V., \& Chan, E. (2008). Multicultural education: Raj’s story using a curricular conceptual lens of the particular. Teaching and Teacher Education, 24, 1705-1716.

Schlein, C., \& Chan, E. (2012). Considering culture in the interpretation of field texts. In E. Chan, V. Ross, \& D. Keyes (Eds.), Narrative inquirers in the midst of meaning-making: Interpretive acts of teacher educators (pp. 109-129). Bingley, UK: Emerald Group Publishing.

Statistics Canada (2003a). Chinese population balloons. Toronto Star, January 22, 2003, A6.

Statistics Canada (2003b). Toronto is leading the way. Toronto Star, January 22, 2003, A6.

Statistics Canada (2003c). Ethnocultural Portrait of Canada. Retrieved January 23, 2003, from http://www12.statcan.ca/English/census01/release/index.cfm

Statistics Canada (2011). Immigration and ethnocultural diversity of Canada. Retrieved June 28, 2013, from http://www12.statcan.gc.ca/nhs-enm/2011/as-sa/99-010-x/99-010-x2011001eng.cfm 
United States Census Bureau, American Community Survey (2010). The foreign-born population in the United States: 2010: American Community Survey Reports. Retrieved June 19, 2013, from http://www.census.gov/prod/2012pubs/acs-19.pdf

United States Census Bureau. (2011). 2010 Census shows America's diversity. Retrieved June 28, 2013, from http://www.census.gov/2010census/news/releases/operations/cb11cn125.html

Valdes, G. (1996). Con respecto: Bridging the distances between culturally diverse families and schools. An ethnographic portrait. New York, NY: Teachers College Press.

Valenzuela, A. (2009). Subtractive schooling, caring relations, and social capital in the schooling of U.S.-Mexican youth. In D. J. Flinders \& S. J. Thornton (Eds.), The curriculum studies reader (3rd ed.) (pp. 336-347). New York, NY: Routledge.

Wong-Fillmore, L. (1991a). When learning a second language means losing the first. Early Childhood Research Quarterly, 6, 323-346.

Wong-Fillmore, L. (1991b). Language and cultural issues in the early education of language minority children. In S.L. Kagan (Ed.), The care and education of America's young children: Obstacles and opportunities. (pp. 30-50). Chicago, IL: The University of Chicago Press.

\section{Notes}

${ }^{i}$ The term curriculum may be used to refer to different kinds of curriculum, including mandated, lived, experienced curriculum, and so on. I refer to the experienced curriculum in most cases in this paper but also make reference to the mandated curriculum.

ii Students who have arrive at Bay Street School with little or no knowledge of English are placed into the ESL

Reception Class until they reach a level of proficiency that enables them to be placed into mainstream classes with same-aged peers.

iii For reasons of privacy and confidentiality, the names of all people and places featured in this research have been replaced with pseudonyms.

Elaine Chan is an associate professor of Diversity and Curriculum Studies in the Department of Teaching, Learning, and Teacher Education, College of Education and Human Sciences at the University of Nebraska-Lincoln. Her research and teaching interests are in the areas of: narrative inquiry; culture and curriculum; teacher education; multicultural education; ethnic identity of first-generation North Americans; student experiences of schooling; and educational equity policies. She has taught and conducted long-term classroom-based research in Canadian, Japanese, and American schools. She co-authored, Teaching the arts to engage English language learners and co-edited Narrative inquirers in the midst of meaning-making: Interpretive acts of teacher educators. Her work has been recognized with an Early Career Award from the American Educational Research Association (AERA) Narrative Research Special Interest Group (SIG), and 
An Interesting Time in My Childhood

publication awards from AERA Division K (Teaching and Teacher Education) and the Narrative Research SIG.

Email: echan2@unl.edu 